\title{
Análise Temporo-Espacial do Uso e Cobertura da Terra na Bacia Hidrográfica do rio Sanabani no Município de Silves - AM nos anos de 1985 e 2019
}

\author{
Temporo-Spatial Analysis of Land Use and Land Cover in the Sanabani River \\ Hydrographic Basin in the Municipality of Silves - AM in 1985 and 2019
}

Análisis Temporo-Espacial del Uso y Cobertura del Suelo en la Cuenca del Río Sanabani en el Municipio de Silves - AM en 1985 y 2019

Leandro Félix de Castro

Mestre em Geografia leandrofelix27@gmail.com

João Cândido André da Silva Neto

Professor Doutor, em Geografia, UFAM, Brasil joaokandido@yahoo.com

\section{Bruno Sarkis Vidal}

Bacharel em Geografia bruno.sarkis.v@gmail.com 


\section{Revista Científica ANAP Brasil}

ISSN 1984-3240 - Volume 14, número 34, 2021

\section{RESUMO}

Em busca de um desenvolvimento sustentável as bacias hidrográficas tornaram-se uma importante unidade de estudo do uso, ocupação e conservação de seus recursos naturais, por haver relações sociais e ecológicas com este ambiente. Neste sentido, a presente pesquisa teve por objetivo analisar a partir de uma perspectiva temporal, as principais mudanças no uso e cobertura da terra que ocorreram entre os anos de 1985 e 2019 na bacia hidrográfica do rio Sanabani, localizado no municípiode Silves-AM. A análise temporo-espacial do uso da terra e cobertura vegetal da bacia hidrográfica do rio Sanabani, possibilitou a identificação da redução de vegetação primária que em 1985 era de 92\%, para atuais $87 \%$ em 2019. Os tipos de uso na bacia são representados principalmente por atividades econômicas do setor primário, onde se destacam a agricultura com o cultivo da mandioca e a pecuária com a criação do gado, onde o município de Silves se destacacom a 26a colocação em Bovinos do Amazonas por Efetivo do rebanho em cabeças.

PALAVRAS CHAVE: Bacia hidrográfica. Uso e Cobertura da Terra. Analise Temporal.

\section{ABSTRACT}

In search of sustainable development, hydrographic basins have become an important unit for studying the use, occupation and conservation of their natural resources, as there are social and ecological relationships with this environment. In this sense, this research aimed to analyze, from a temporal perspective, the main changes in land use and land cover that occurred between 1985 and 2019 in the Sanabani river basin, located in the municipality of SilvesAM. The temporal-spatial analysis of land use and vegetation cover in the Sanabani River watershed made it possible to identify the reduction of primary vegetation from $92 \%$ in 1985 to $87 \%$ in 2019. The types of use in the basin are represented mainly due to economic activities in the primary sector, where agriculture with the cultivation of cassava and cattle raising with cattle raising stand out, where the municipality of Silves stands out with the 26th place in Bovinos do Amazonas for Effective herd in heads.

KEYWORDS: Hydrographic basin. Land Use and Coverage. Temporal Analysis.

\section{RESUME}

En busca del desarrollo sostenible, las cuencas hidrográficas se han convertido en una unidad importante para el estudio del uso, ocupación y conservación de sus recursos naturales, ya que existen relaciones sociales y ecológicas con este medio. En este sentido, esta investigación tuvo como objetivo analizar, desde una perspectiva temporal, los principales cambios de uso y cobertura del suelo ocurridos entre 1985 y 2019 en la cuenca del río Sanabani, ubicada en el municipio de Silves-AM. El análisis temporal-espacial del uso del suelo y la cobertura vegetal en la cuenca del río Sanabani permitió identificar la reducción de la vegetación primaria del 92\% en 1985 al $87 \%$ en 2019. Los tipos de uso en la cuenca están representados principalmente para actividades económicas en el sector primario, donde se destaca la agricultura con el cultivo de yuca y la ganadería con ganadería, donde se destaca el municipio de Silves con el puesto 26 en Bovinos do Amazonas por número de rebaños en cabezas.

PALABRAS CLAVE: Cuenca hidrográfica. Uso y cobertura del suelo. Análisis temporal. 


\section{Revista Científica ANAP Brasil}

ISSN 1984-3240 - Volume 14, número 34, 2021

\section{INTRODUÇÃO}

A Floresta Amazônica é a maior floresta tropical com clima equatorial quente e úmido e, junto com a Bacia Amazônica, formam um dos mais importantes ecossistemas do planeta. De acordo com Ferreira (2012), na Amazônia, observa-se um mosaico de três principais estruturas florestais, sendo a primeira, a floresta de várzea, a segunda floresta de igapó e a terceira a floresta de terra firme.

$A b^{\prime}$ Saber (2003), afirma que a Amazônia está no cinturão de máxima diversidade biológica, e destaca-se pela extraordinária continuidade de suas florestas, pela ordem de grandeza de sua rede hidrográfica, e por sutis variações do seu ecossistema.

Diante disto, "a busca por respostas que viabilizem uma melhor utilização dos recursos naturais e uma relação mais harmônica entre sociedade e natureza, tem levado à novas abordagens nas pesquisas geográficas" (CAMPOS, 2008, p. 12), surgindo então estudos de cunho ambiental (MENDONÇA, 2001).

Embora haja políticas e planejamentos voltados ao meio ambiente com o intuito de conciliar desenvolvimento e preservação, Gomes (1988), enfatiza que os índices de agressão à natureza e à sociedade atingem valores catastróficos, não conciliando na prática o desenvolvimento econômico com preservação da natureza.

Em relação a região amazônica, o discurso de uma política nacionalista adotada pelo regime militar é um dos pontos de partida para a ocupação da Amazônia, sendo intensificado através de programas de incentivos de ocupação e de produção para esta região.

Venturieri et al., (2010), confirma que o Programa de Integração Nacional (PIN) instituído pelo decreto-lei 1.106, de 16 de julho de 1970, durante o regime militar, foi um dos processos determinantes para a ocupação da Amazônia brasileira a partir da década de 1970, e que esta região apresenta um acelerado processo de substituição de sua cobertura vegetal oriundos de atividades antrópicas.

Atualmente, no cenário da Amazônia Legal, o processo de ocupação de forma desordenada gera impactos de difícil ou nenhuma solução, pois a alteração da paisagem e do uso da terra deve-se principalmente à utilização do solo com atividades agropecuárias e de mineração, que nem sempre são adequadas para o ambiente Amazônico (MOREIRA, 2008; SANTOS, 2013).

Higuchi e Higuchi (2012, p. 12), afirmam que "dessa forma, o desmatamento, associado ao mau uso dos recursos naturais da Amazônia, tem sido motivo de preocupação no cenário internacional, com a possibilidade de intensificar a crise ambiental que o planeta tem sido acometido principalmente nas últimas cinco décadas".

Diante disto, o desmatamento contribui e evidencia a ocorrência de processos erosivos, pois a retirada da cobertura vegetal reduz a capacidade de retenção de água, comprometendo os recursos hídricos. Tal constatação, nos leva também a compreensão do quanto interferência humana pode intensificar o processo de degradação ambiental e perturbar as dinâmicas e os processos naturais.

Turetta (2011), considera ainda que o estudo para a análise da mudança de uso e cobertura da terra nos permite entender os processos de alteração no espaço geográfico, e são importantes devido à necessidade de conhecimento da fragilidade das terras e de seus recursos naturais.

A grande dimensão da bacia Amazônica é grande desafio para a gestão e manutenção 


\section{Revista Científica ANAP Brasil}

ISSN 1984-3240 - Volume 14, número 34, 2021

de políticas relacionadas a um desenvolvimento sustentável, indispensável para este recurso hídrico por sofrer com a degradação ambiental devido ao precário saneamento básico, poluição dos rios por atividades mineradoras, garimpos legais ou clandestinos, desmatamento, avanços da fronteira agropecuária etc.

Em busca de um desenvolvimento sustentável as bacias hidrográficas tornaram-se uma importante unidade de estudo do uso, ocupação e conservação de seus recursos naturais, por haver relações sociais e ecológicas com este ambiente.

Neste sentido, a presente pesquisa teve por objetivo analisar a partir de uma perspectiva temporal, as principais mudanças no uso e cobertura da terra que ocorreram entre os anos de 1985 e 2019 na bacia hidrográfica do rio Sanabani, localizado no municípiode SilvesAM.

A presente pesquisa é importante ainda por tratar da interação e apropriação da sociedade na natureza, que se evidencia nos diferentes tipos de uso e ocupação da terra, podendo levar a processos de degradação ambiental tais como processos erosivos, assoreamento dos rios, desmatamento, poluição e desvio dos cursos d'água na bacia estudada.

\section{OBJETIVO}

Analisar o uso da terra e cobertura vegetal na bacia hidrográfica do rio Sanabani dos anos de 1985 a 2019.

\subsection{Objetivos específicos}

Classificar o uso da terra e cobertura vegetal.

Analisar o uso da terra e da cobertura vegetal numa perspectiva temporal.

\section{METODOLOGIA}

\subsection{Localização da área de estudo}

A bacia hidrográfica do rio Sanabani está localizada integralmente no município de Silves no Estado do Amazonas, possuindo uma área aproximada de $670 \mathrm{~km}^{2}$ de extensão.

Segundo Albuquerque (1999), Silves é um dos municípios amazonenses iniciados por missionários que se instalaram na Amazônia, com sua fundação em 1660 com o nome de Saracá, no rio Urubu, por Frei Raimundo da Ordem das Mercês.

O município localiza-se na região do médio Amazonas, distante da capital amazonense cerca de $250 \mathrm{~km}$ por via fluvial, e terrestre percorre-se $226 \mathrm{~km}$ da estrada AM-010 (ManausItacoatiara) e mais 127 km da BR-363. Tem seus limites com os municípios de Itapiranga, Urucurituba e Itacoatiara (FARIA, 2010). Possui uma população estimada de 9.171 habitantes distribuído em um território $3.723,382$ km² (IBGE, 2019).

\subsection{Mapeamento do uso da terra e cobertura vegetal}

Para a criação dos mapas de análise de uso e cobertura da terra, foram utilizadas as imagens do satélite Landsat 5 MSS para o ano de 1985, com uma resolução espacial de 80 metros, e Landsat 8 OLI para o ano de 2019, com resolução espacial de 30 metros, sendo que as imagens são disponibilizadas pelo site do United States Geological Survey (USGS) (Tabela 01). 


\section{Revista Científica ANAP Brasil}

ISSN 1984-3240 - Volume 14, número 34, 2021

Tabela 01 - Imagens de satélite utilizadas para análise temporal e mudança de uso e cobertura da terra no município de Silves.

\begin{tabular}{|l|l|l|l|l|l|}
\hline \multicolumn{1}{|c|}{ Satélite } & Sensor & Resolução & Bandas & Data de aquisição & $\begin{array}{c}\text { Órbita/Pont } \\
0\end{array}$ \\
\hline Landsat -5 & MSS & $80 \mathrm{~m}$ & $2,3,4$ & $01 / 09 / 1985$ & $230 / 62$ \\
\hline Landsat -8 & OLI & & & & $230 / 62$ \\
\hline
\end{tabular}

Fonte: INPE. Elaboração: Leandro Felix, (2020).

Os mapas de uso e cobertura da terra foram divididos em 05 classes temáticas (vegetação primária, vegetação secundária, solo exposto, pastagens e corpos d'água). Estas classes estão de acordo com o nível I do Sistema Básico de Classificação da Cobertura e do Uso da Terra (SCUT), do Manual Técnico de Uso da Terra do IBGE (2013). Segundo o IBGE (2013):

O nível I (classes), que contém cinco (5) itens, indica as principais categorias da cobertura terrestre no planeta, que podem ser discriminadas a partir da interpretação direta dos dados dos sensores remotos. Atendem aos usuários interessados em informações nacionais ou inter-regionais (p. 10).

A etapa seguinte consistiu no processamento digital das imagens, onde foram utilizados os softwares QGIS e SPRING. Segundo Santos et. al. (2010), as técnicas de processamentodigital de imagens podem ser divididas em três etapas: pré-processamento, realce de imagens e análise de imagens.

No software QGIS, foi elaborada a composição colorida das bandas do vermelho (RED), infravermelho próximo (NIR) e infravermelho médio (IV Médio), para facilitar a interpretação de imagens, possibilitando a identificação de feições e objetos. Utilizou-se dos limites da bacia hidrográfica para realizar o recorte da área de estudo.

Após esta etapa, as imagens foram importadas para o Spring para então, com as imagens recortadas, iniciar a segmentação de imagens, juntamente com a classificação supervisionada por regiões utilizando o classificador Bhattacharya.

A primeira etapa no processo de classificação é a segmentação. Segundo Santos et. al. (2010), o ato de segmentar uma imagem consiste em agrupar pixels com características similares em termos tonais e texturais, formando regiões homogêneas. Para Lopes (2005), neste processo, divide-se a imagem em regiões que devem corresponder àsáreas de interesse da aplicação, tais regiões são um conjunto de "pixels" contíguos, que se espalham bi-direcionalmente, apresentando uniformidade.

Após a segmentação da imagem, foi realizado o processo de treinamento, que está relacionado à aquisição de amostras na imagem dividida por regiões, onde atribui-se uma determinada classe para a amostra coletada (SANTOS, et. al. 2010).

No que tange à classificação supervisionada por região utiliza informação espectral de cada "pixel" e a informação espacial que envolve a relação entre os "pixels" e seus vizinhos, tais classificadores simulam o comportamento de uma foto intérprete, ao reconhecer áreas homogêneas de imagens, baseado nas propriedades espectrais e espaciais de imagens (SANTOS, et. al. 2010).

O classificador de Bhattacharya é um algoritmo de classificação supervisionada, de acordo com Santos et. al. (2010), o mesmo requer a seleção de áreas de treinamento, podendo 


\section{Revista Científica ANAP Brasil}

ISSN 1984-3240 - Volume 14, número 34, 2021

utilizar as regiões separadas durante o processo de segmentação ou polígonos representativos das regiões a serem classificada.

O procedimento de pós-classificação sedimenta-se no refinamento da classificação do uso da terra, compondo-se na extração de pixels isolados. No caso daqueles que não foram classificados, em função de um limiar ou um peso, fornecidos pelo usuário, utilizou-se o padrão do Spring.

Finalizou-se esta etapa de classificação com a transformação da imagem classificada (categoria Imagem) para um mapa temático raster, possibilitando que o plano de informação entre na análise temporal do uso da terra por meio de álgebra de mapas, implementada a partir de operadores Booleanos.

Segundo Fitz (2008), a sobreposição lógica, caracteriza-se por utilizar operadores lógicos, ou seja, por utilizar a Lógica Booleana. Esse tipo de sobreposição trabalha com arquivos normalmente matriciais, a partir da sobreposição de diferentes camadas de dados.

Assim, pode-se atribuir às operações lógicas-booleanas que:

Estas funções utilizam operadores lógicos (booleanos) e permitem realizar cruzamentos entre dois ou mais planos de informação. $A$ operação lógica do tipo $A$ AND $B$ retorna todos os elementos contidos na intersecção entre A e B; A NOT B retorna somente os elementos contidos exclusivamente em $A ; A$ OR B retorna todos elementos contidos tanto em $A$ como em $B$; A XOR B retorna todos os elementos contido em A e B não incluídos na intersecção de A e B. (CÂMARA et al. 2001b, p. 216).

Abaixo segue o código de programação criado em Linguagem Espacial Para Geoprocessamento Algébrico (LEGAL), que utilizou os operadores Booleanos na análise espacial para gerar o mapa síntese de análise temporo-espacial do uso da terra e cobertura vegetal da área de estudo.

\{

\section{//declaracoes}

Tematico usoini ("USO_1989");

Tematico usofim ("USO_2019");

Tematico temporal ("MULTITEMPORAL");

//instanciacoes

usoini = Recupere( Nome = "1989" );

usofim = Recupere( Nome = "2019SILVES" );

temporal $=$ Novo $($ Nome $=$ "MULTITEMPORAL_89_19", ResX $=30$, ResY $=30$, Escala $=60000)$;

//operacoes 


\section{Revista Científica ANAP Brasil}

ISSN 1984-3240 - Volume 14, número 34, 2021

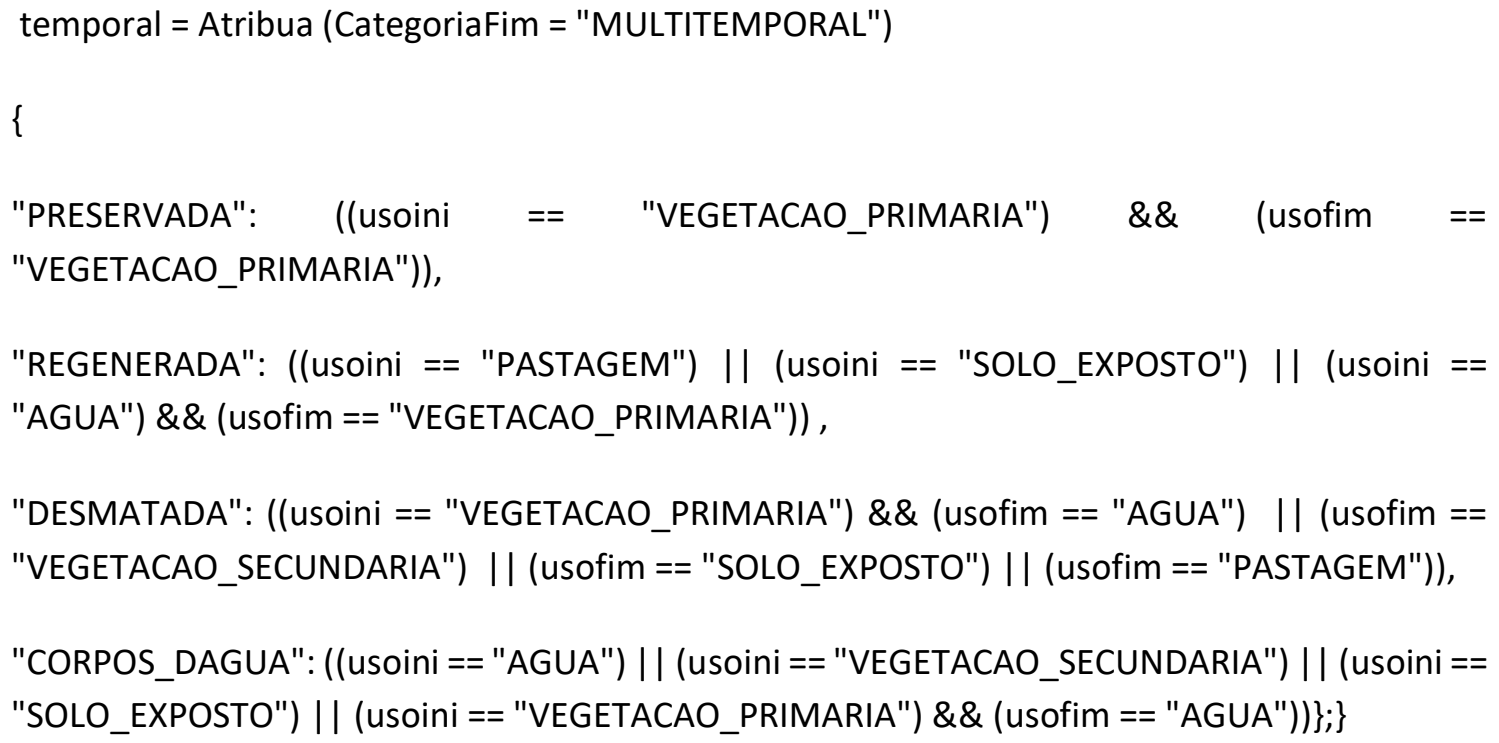

\section{RESULTADOS}

Os resultados do mapeamento de uso da terra e cobertura vegetal na bacia hidrográfica do rio Sanabani, fornecem informações da área estudada em busca de uma melhor compreensão da dinâmica do uso e ocupação da terra, bem como seus impactos ambientais causados na área de estudo.

Neste sentido, os alvos de interesse foram destacados em cinco classes representadas em mapas temáticos. Os mapas foram selecionados a partir das imagens de satélite referentes aos anos de 1985 e 2019. Todos foram relacionados e analisados, evidenciando as modificações ocorridas no uso e cobertura terra.

A escolha inicial a partir do ano de 1985 se dá pelo fato de na época não haver a construção das rodovias estaduais AM-363 e a AM-330. Neste período, no começo da década de 1980, a grande maioria dos habitantes de Silves (83\%) ainda residia em áreas rurais (GIGLIOTTI, 2015).

Segundo Ribeiro (1991), as rodovias AM-363 e 330 foram inauguradas somente em dezembro de 1987, tornando-se posteriormente a principal ligação via terrestre do município de Silves a capital Manaus.

Embora a estrada tenha permitido o fim do isolamento por via terrestre ao município de Silves, a mesma levantou uma série de indagações, como o porquê de, no lugar de uma estrada de difícil conservação por causa da erosão, causada pelos altos índice de pluviosidade que caem na região, não se providenciou uma frota de barcos para o transporte da produção agrícola por vias naturais que são os rios (RIBEIRO, 1991).

Ribeiro (1991), afirma ainda que a região é rica em vários tipos de minério, e questiona se a estrada teria sido construída com a finalidade de transportar minérios tal como já acontecia com a BR-174.

Em relação aos dados do mapeamento da bacia do rio Sanabani destacados nas classes referente ao ano de 1985 (Figura 02), verificou-se que a área da bacia apresentava um total de $613,14 \mathrm{~km}^{2}$ de vegetação primária, representando $92,28 \%$ da área total da bacia, enquanto a vegetação secundária apresentou um total de $24,78 \mathrm{~km}^{2}$, representando $3,73 \%$ da área.

Em relação às áreas de pastagem, esta classe possuía uma área total de $5,16 \mathrm{~km}^{2}$, 
correspondendo $0,78 \%$, as classes de solo exposto possuíam um total de $0,85 \mathrm{~km}^{2}$, correspondendo a $0,13 \%$ da área total.

Figura 01 - Mapa de Uso da terra e Cobertura vegetal da Bacia Hidrográfica do Rio Sanabani em 1985.

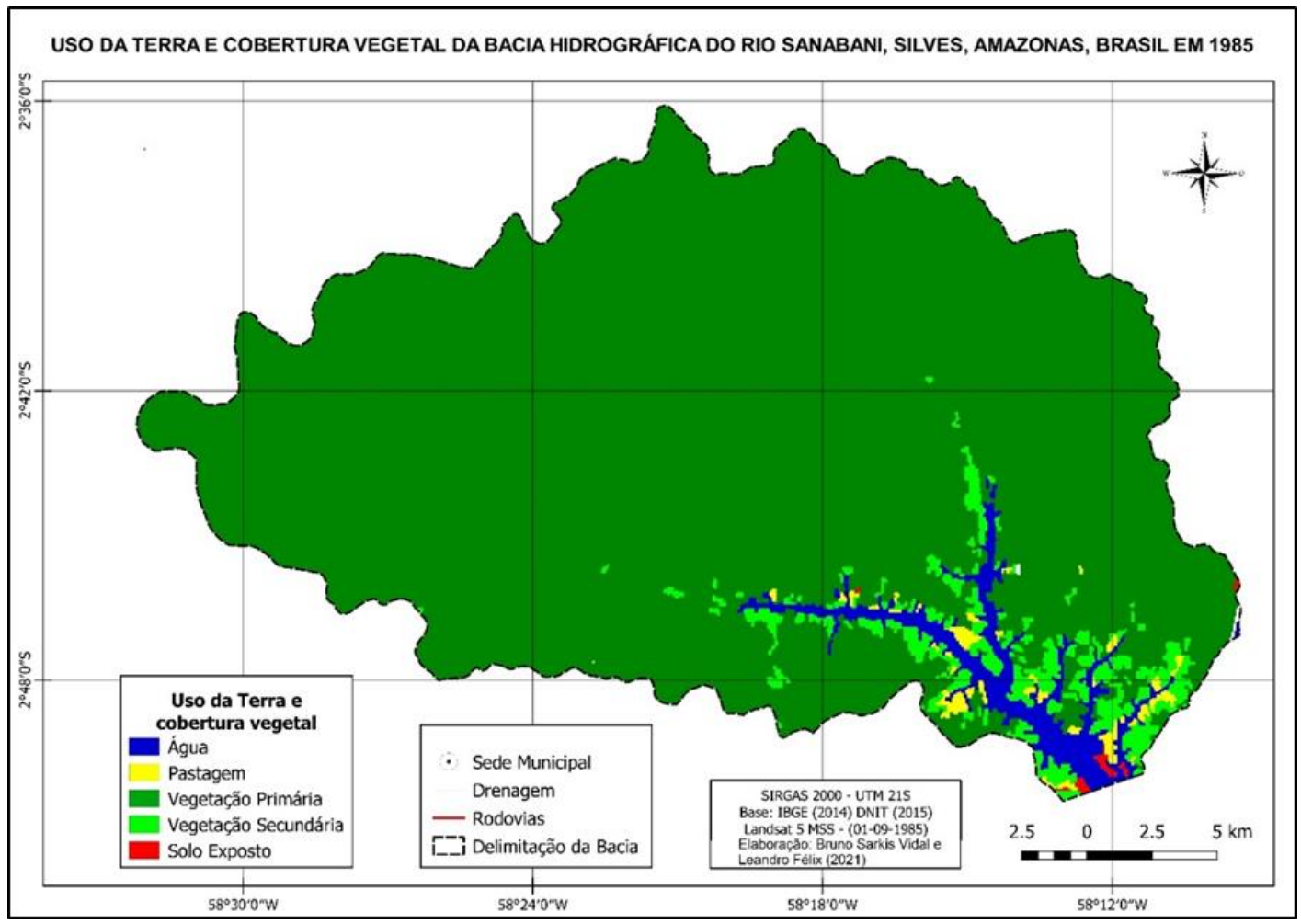

Fonte: IBGE, 2010. Elaboração Bruno Sarkis, Leandro Felix, (2021).

O mapeamento de uso e cobertura da terra da bacia referente ao ano de 2019 (Figura 03), indica uma redução da vegetação primária, que apresenta atualmente uma área total de 575 $\mathrm{km}^{2}$, representando uma porcentagem de $86,57 \%$. Já a vegetação secundária apresenta um aumento $43 \mathrm{~km}^{2}$, evidenciando atuais $6,41 \%$.

As áreas de pastagens apresentam uma área total de $25 \mathrm{~km}^{2}$, representando atuais $3,77 \%$. Já as áreas de solo exposto possuem atuais $2 \mathrm{~km}^{2}$, representando apenas $0,27 \%$ do total da bacia, mantendo-se como a classe que apresentou pouca representatividade em comparação com as outras classes analisadas.

Na comparação dos dados referente aos anos de 1985 e 2019, foi possível observar as variações e a dinâmica de uso e ocupação da terra ocorridas em cada classe, ocorridas antes e do depois da construção das rodovias AM-330 e AM-363, indicando uma redução crescente da vegetação primária (Tabela 02).

Observa-se ainda que a intensificação da dinâmica de uso ocupação da terra da bacia ocorre principalmente nas porções sul e sudeste, a partir das margens dos rios Itapani e Sanabani para o interior da bacia, e posteriormente a partir das rodovias AM- 363 e AM-330.

Segundo Gigliotti (2015), a construção da rodovia AM-363 transformou a dinâmica populacional e de ocupação humana na região, transferindo a ocorrência das principais áreas desflorestadas dos rios para as estradas. 


\section{Revista Científica ANAP Brasil}

ISSN 1984-3240 - Volume 14, número 34, 2021

Figura 02: Mapa de Uso da Terra e Cobertura Vegetal da Bacia Hidrográfica rio Sanabani em 2019.

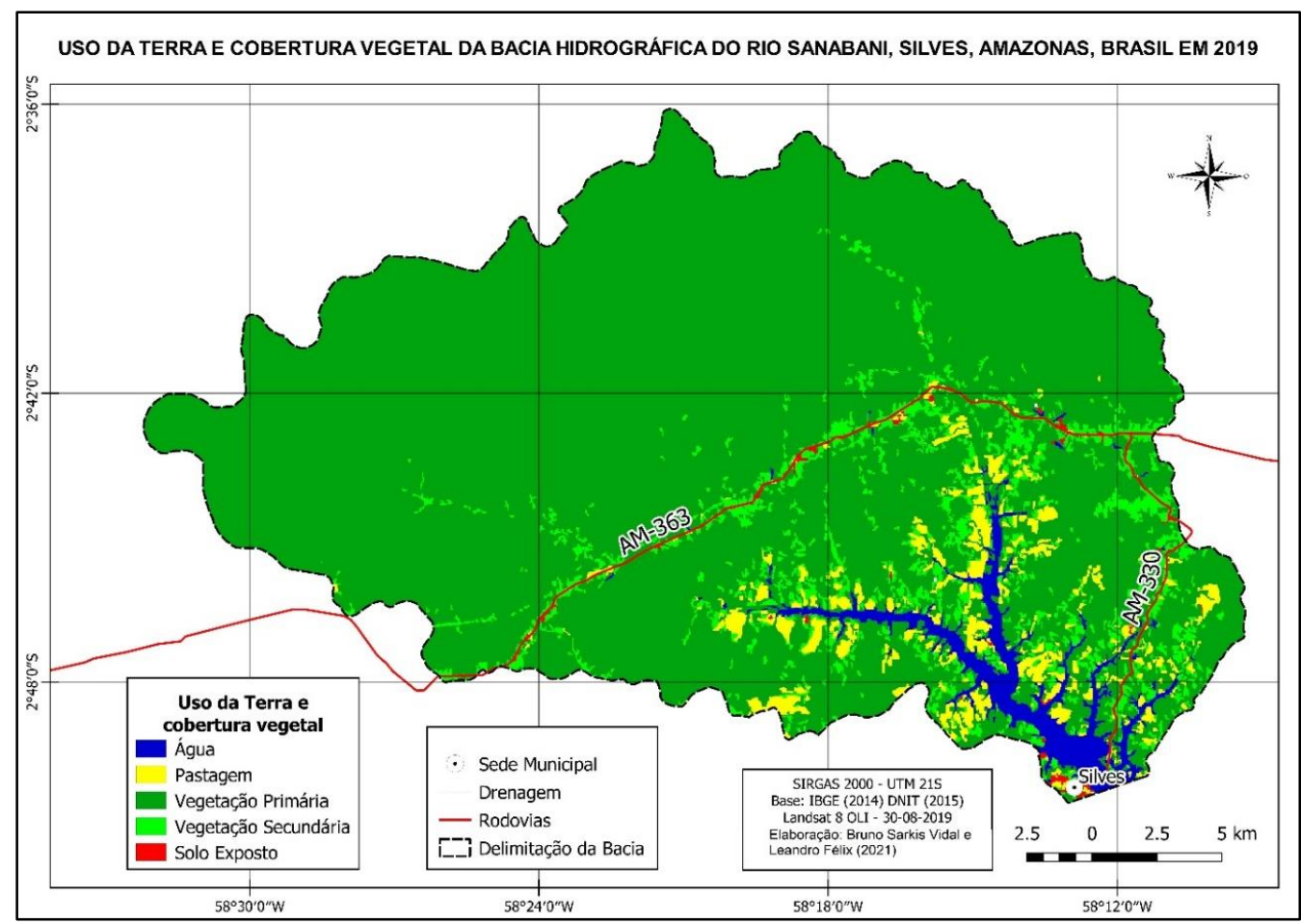

Fonte: IBGE, 2010. Elaboração Bruno Sarkis, Leandro Felix, (2021).

Constatou-se, ainda, que as margens dos rios da bacia do rio sanabani são ocupadas principalmente pelas atividades agropecuárias, com culturas principalmente da mandioca e a criação de bovinos e bubalinos, com a maior representatividade de animais de grande porte, outra ocupação que se destaca é a urbana, com casas construídas as margens dos rios Sanabani e Itapani e na sede municipal de Silves.

Tabela 02 - Classes de uso da terra e cobertura vegetal na bacia hidrográfica do rio Sanabani em 1985 e 2019.

\begin{tabular}{|c|c|c|c|c|}
\hline \multicolumn{1}{|c|}{ Classes } & \multicolumn{2}{|c|}{2019} \\
\hline & área em km² & área em \% & área em km² & área em \% \\
\hline Água & 20,53 & 3,09 & 20 & 2,97 \\
\hline Vegetação primária & 613,14 & 92,28 & 575 & 86,57 \\
\hline Vegetação secundária & 24,78 & 3,73 & 43 & 6,41 \\
\hline Pastagem & 5,16 & 0,78 & 25 & 3,77 \\
\hline Solo exposto & 0,85 & 0,13 & 2 & 0,27 \\
\hline Total & 664,46 & 100 & 664 & 100 \\
\hline
\end{tabular}

Elaboração: Leandro Felix, (2021).

Quanto à análise multitemporal do uso da terra e cobertura vegetal da Bacia Hidrográfica do Rio Sanabani nos anos de 1985 e 2019, verificou-se que no período analisado que, atualmente $84 \%$ da área total da Bacia, mantem-se preservada, isso significa que essas áreas foram classificadas no mapeamento de Uso da Terra e Cobertura Vegetal de 1985 e 2019 


\section{Revista Científica ANAP Brasil}

ISSN 1984-3240 - Volume 14, número 34, 2021

como vegetação primária (Gráfico 01).

Gráfico 01 - Análise multitemporal do Uso da Terra e Cobertura Vegetal da Bacia Hidrográfica do Rio Sanabani dos anos de 1985 e 2019.

ANÁLISE MULTITEMPORAL DO USO DA TERRA
NA BACIA HIDROGRÁFICA DO RIO SANABANI

ENTRE 1985 A 2019

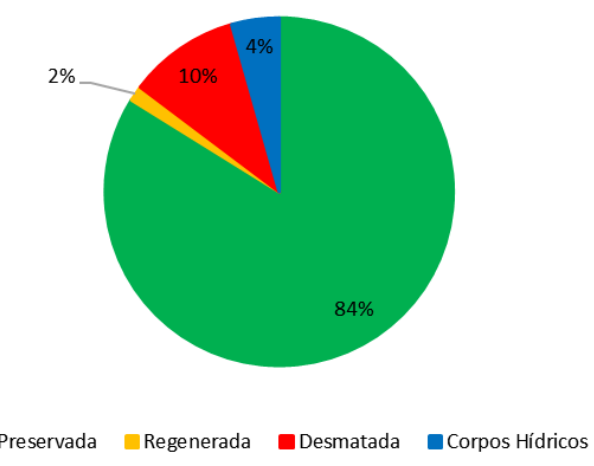

Elaboração: Leandro Félix, (2021).

Quanto as áreas classificadas como desmatadas na comparação multitemporal dos anos de 1985 a 2019, as mesmas apresentam atualmente $10 \%$ do total da bacia. No mapeamento de uso e cobertura da terra nos de 1985 e 2019 estas áreas foram classificadas com vegetação segundaria, ou seja, áreas com pastagens, atividades agrícolas e áreas urbanas.

Em relação as áreas de regeneração da vegetação verificaram-se que elas representam atuais 2\% do total da bacia, estas áreas em 1985 eram classificadas como pastagens ou solo exposto. Tais áreas de reflorestamento podem ser relacionadas à regeneração natural da vegetação onde possivelmente haviam sido pastagem ou áreas de atividades agrícolas (figura 04).

Atualmente as atividades de uso, ocupação e cobertura da terra da bacia hidrográfica do rio Sanabani estão historicamente baseadas na pecuária, agricultura, o extrativismo mineral e vegetal, e a pesca artesanal, todos com um importante papel no desenvolvimento econômico e social da área de estudo no decorrer das últimas décadas.

Entretanto, juntamente com estas atividades ocorrem impactos ambientais como a intensificação de processos erosivos.

De acordo com Sales (2005), as principais atividades econômicas, desenvolvidas no município Silves, são o extrativismo vegetal, a pesca, a agropecuária e a exploração mineral.

A produção agrícola é baseada no cultivo de mandioca, enquanto a pecuária é representada principalmente por bovinos e suínos, com produção de carne e de leite destinada ao consumo local, em relação pesca, esta é praticada de forma artesanal, e a extração vegetal, destaca-se a castanha (Bertholletia excelsa) (SALES, 2005).

Malveira (2009), afirma que a criação de bovinos, suínos e búfalos são responsáveis por $77 \%$ do setor primário do município de Silves, destaca ainda a mandioca como a principal atividade da agricultura, no setor secundário a principal atividade de exploração é a madeira, no setor terciário hotéis restaurantes, e o ecoturismo. 
Figura 03 - Análise multitemporal da Bacia Hidrográfica do Rio Sanabani dos anos de 1985 e 2019.

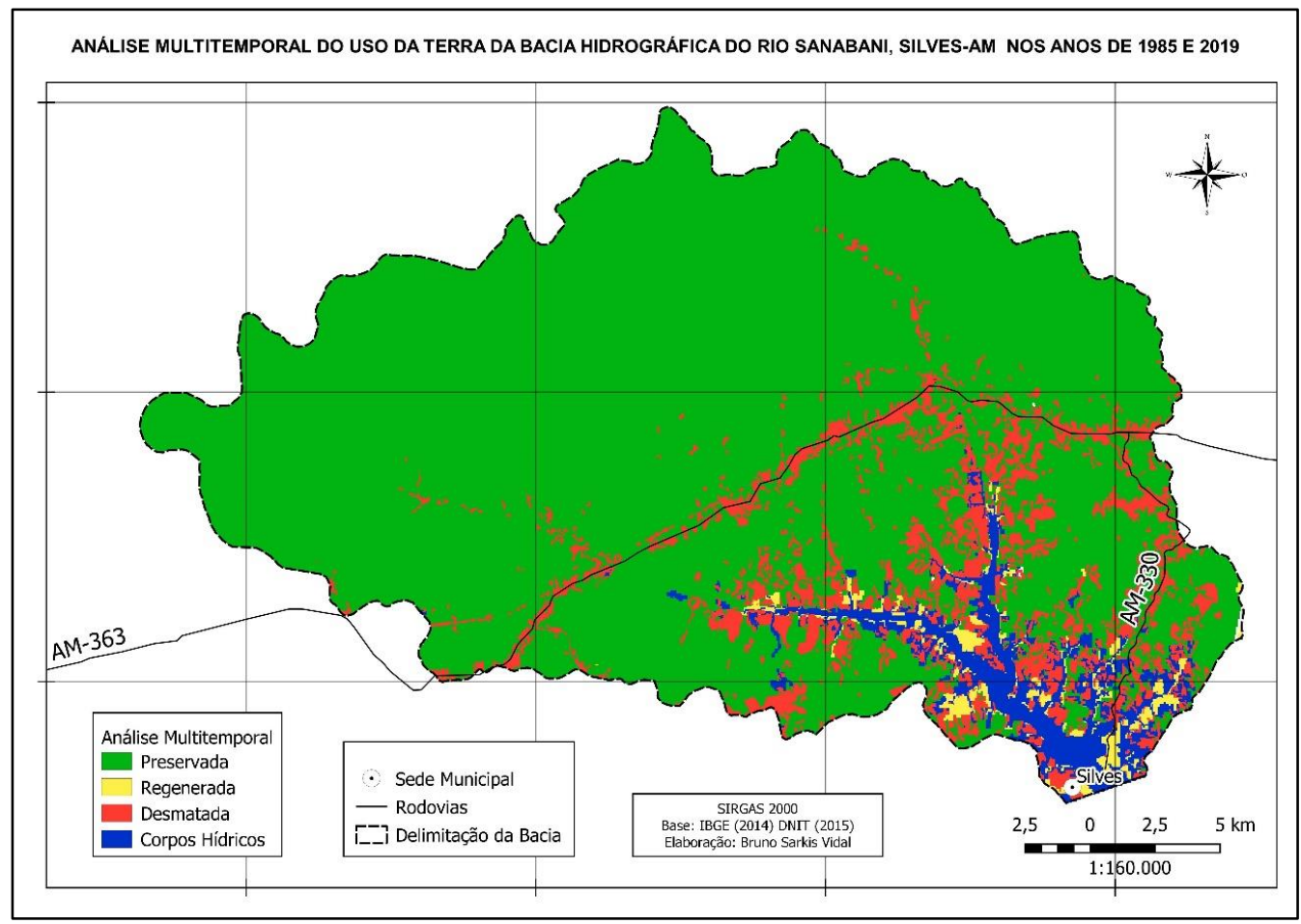

Fonte: IBGE, 2010. Elaboração Bruno Sarkis, Leandro Felix, (2021).

Atualmente, segundo o censo agropecuário no ano de 2017 apontava que Silves está na 26a colocação em Bovinos do Amazonas, por Efetivo do rebanho em cabeças.

A tabela 03 nos mostra a evolução do efetivo rebanho dos principais animais de grande (bovinos, bubalinos e equinos) e médio porte (suínos), onde a espécie bovina é a que possui maior quantitativo de rebanhos seguido com a de suínos que ocupa a segundaposição da atividade da pecuária.

Tabela 03 - Evolução do efetivo da pecuária de animais de grande porte.

\begin{tabular}{|c|c|c|c|c|c|}
\hline Animais & 1985 & 1989 & 1999 & $2009 * 1997$ & 2019 \\
\hline Bovinos & 7.655 & 13.561 & 17.837 & 14.634 & 11.726 \\
\hline Bubalinos & 151 & 688 & 2.142 & 888 & 360 \\
\hline Equinos & 192 & 220 & 86 & 113 & 525 \\
\hline Suínos & 3.029 & 4.796 & 8.461 & 1.108 & 1.635 \\
\hline
\end{tabular}

Fonte: IBGE - Pesquisa Pecuária Municipal. *Dados referentes ao ano de 1997.

A exploração mineral está presente às margens do rio Sanabani com extração da areia destinada a construção civil. Riker et. al. (2008), afirma que a areia possui uma razoável distribuição na área de estudo e em grande parte vem sendo utilizada na construção civil, e que a maior parte dos areais corresponde a produto de podzolização desenvolvido sobre rochas areníticas das formações Alter do Chão e Novo Remanso. 


\section{Revista Científica ANAP Brasil}

ISSN 1984-3240 - Volume 14, número 34, 2021

\section{CONCLUSÃO}

A análise dos processos de apropriação da natureza que, manifestados por meio dos diferentes tipos de uso da terra, identificados por meio do sensoriamento remoto, Sistemasde Informações Geográficas (SIG) e trabalhos de campo, permitiram a classificação, quantificação do uso e cobertura da terra, assim como as alterações causadas nas paisagens da bacia hidrográfica do rio Sanabani.

Em comparação ao tempo de análise (1985 a 2019), a bacia do rio Sanabani vem apresentando, mesmo não sendo muitoexpressiva, uma redução de sua vegetação primária, concentrada principalmente às margens de suas rodovias e dos rios Itapani e Sanabani.

A análise temporo-espacial do uso da terra e cobertura vegetal da bacia hidrográfica do rio Sanabani, possibilitou a identificação da redução de vegetação primária que em 1985 era de $92 \%$, para atuais $87 \%$ em 2019 .

Na contemporaneidade, os tipos de uso na bacia são representados principalmente por atividades econômicas do setor primário, onde se destacam a agricultura com o cultivo da mandioca e a pecuária com a criação do gado, onde o município de Silves se destacacom a 26a colocação em Bovinos do Amazonas por Efetivo do rebanho em cabeças.

\section{REFERÊNCIAS}

ALBUQUERQUE, Albertina. Amazônia Brasileira Ocidental: aspectos geográficos e históricos. Manaus: Editora da Universidade Federal do Amazonas - EDUA, 1999, 132 p.

CÂMARA, G. et al. Álgebra de mapas, In: CÂMARA, G.; DAVIS, C. e MONTEIRO, A. M. V. Introdução à Ciência da Geoinformação. São José dos Campos. INPE10506-RPQ/249, 2001b. 221- 240 p.

CAMPOS, D. C. Dinâmica de uso e ocupação da terra na bacia hidrográfica do Arroio dos Pereiras em Irati - PR e sua influência na qualidade das águas superficiais. 2008. 110 f. Dissertação (Mestrado em Gestão do Território) Universidade Estadual de Ponta Grossa, Ponta Grossa, 2008.

FARIA, Ivani Ferreira de. Gestão territorial e Mapeamento participativo na Reserva de Desenvolvimento Sustentável (RDS) de Saracá Piranga/Silves-AM. In: vi seminário latino-americano de geografia física Il seminário ibero-americano de geografia física, 6., 2010, Coimbra. Expansão e democratização das novas tecnologias em Geografia Física: aplicações emergentes. Coimbra: Universidade de Coimbra, 2010.

FERREIRA, Sávio José Figueiras. Floresta e a água. In. HIGUCHI, Maria Inês gasparetto; HIGUCHI, Niro. A floresta amazônica e suas múltiplas dimensões: Uma proposta de educação ambiental. 2. ed. Manaus: Fapeam, 2012. Cap. 5. p. 123-151.

FITZ, Paulo Roberto. Geoprocessamento sem complicação. São Paulo: Oficina de Textos, 2008.

GIGLIOTTI, Eduardo da Silva. Explorando a gestão compartilhada dos recursos naturais: 0 caso dos acordos de pesca de Silves-AM. São José dos Campos: INPE, 2015. Tese (Doutorado em Ciência do Sistema Terrestre) - Instituto Nacional de Pesquisas Espaciais, São José dos Campos, 2015.

GOMES, Horieste. A Questão Ambiental: Idealismo e Realismo Ecológico. In: VESENTINI, José William (Ed.). Geografia e Questão ambiental. São Paulo: Marco Zero, 1988. Cap. 3. p. 33-54.

HIGUCHI, Maria Inês Gasparetto; HIGUCHI, Niro. A floresta amazônica e suas múltiplas dimensões: uma proposta de educação ambiental. 2. ed. Manaus, 2012. 424 p.

IBGE, Instituto Brasileiro de Geografia e Estatística. Manual técnico de uso da terra. Coordenação de Recursos Naturais e Estudos Ambientais. - 3. ed. - Rio de Janeiro: IBGE, 2013. 171 p. 


\section{Revista Científica ANAP Brasil}

ISSN 1984-3240 - Volume 14, número 34, 2021

LOPES, EYMAR. Spring básico: Tutorial 10 aulas -Spring 4.2 (Versão Windows). Revisão: Hilcéa Santos Ferreira. Instituto Nacional de Pesquisas Espaciais -, Setembro de 2005.

MALVEIRA, willian. Economia \& Horizontes da Amazônia. Manaus: editora: valer. 2009. 114p.

MENDONÇA, F. Geografia socioambiental. In: revista terra livre, n 16, p. 113-132, 10 semestre, 2001.

MOREIRA, A. M. Estudo comparativo do uso da terra em unidades de produção familiar no Nordeste. $2008.87 \mathrm{f}$. Dissertação (Mestrado em Ciências Ambientais) - Universidade Federal do Pará, Belém, 2008.

RIBEIRO, Sylvia Aranha de Oliveira. Vida e Morte no Amazonas. São Paulo: editora Loyola, 1991.

RIKER, Silvio Roberto Lopes, REIS Nelson Joaquim, D`ANTONA Raimundo de Jesus Gato, BRITO Ivens de Araújo. Projeto Materiais de construção no domínio médio Amazonas. Manaus: CPRM - Serviço Geológico do Brasil, 2008. RIBEIRO, Sylvia Aranha de Oliveira. Vida e Morte no Amazonas. São Paulo: editora Loyola, 1991.

SALES, Janaína Paolucci. Agricultura Familiar de Várzea: Componentes do Sistema de Produção Pecuária. 2005. 139 f. Dissertação (Mestrado) - Curso de Ciências Biológicas, Universidade Federal do Amazonas, Manaus, 2005.

SÁBER, Aziz Nacib Ab'. Os Domínios de Natureza no Brasil: Potencialidades paisagísticas. 7. ed. São Paulo: Ateliê Editorial, 2003.

SANTOS, Alexandre, PELUZIO Telma; SAITO Nathália. SPRING 5.1.2: passo a passo: aplicações práticas /. - Alegre, ES: CAUFES, 2010. $153 \mathrm{p}$.

SANTOS, D. B. O. Aplicação da Rusle a uma pequena bacia hidrográfica da Amazônia. 2013. 82 f. Dissertação (Mestrado em Engenharia Civil) - Universidade Federal do Pará, Belém, 2013.

TURETTA, Ana Paula Dias. Mudanças de Uso da Terra em Bacias Hidrográficas. Rio de Janeiro: Embrapa Solos, 2011. $18 \mathrm{p}$.

VENTURIERI, Adriano et al. Uso da Terra. In: VENTURIERI, Adriano; MONTEIRO, Marcílio de Abreu; MENEZES, Carmen Roseli Caldas (Org.). Zoneamento ecológico- econômico da Zona Oeste do Estado do Pará. Belém: Embrapa Amazônia. 